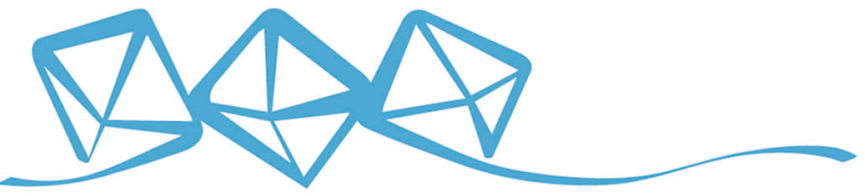 COMMUNICATIONS MATERIALS
}

ARTICLE

https://doi.org/10.1038/s43246-020-00109-8

OPEN

\section{Shaping and silane coating of a diamine-grafted metal-organic framework for improved $\mathrm{CO}_{2}$ capture}

Jong Hyeak Choe ${ }^{1}$, Jeoung Ryul Park ${ }^{1}$, Yun Seok Chae ${ }^{1}$, Dae Won Kim¹, Doo San Choi ${ }^{1}$, Hyojin Kim', Minjung Kang${ }^{1}$, Hwimin Seo ${ }^{2}$, Yong-Ki Park² \& Chang Seop Hong ${ }^{1 凶}$

Although metal-organic framework (MOF) powders can be successfully shaped by conventional methods, postsynthetic functionalization of the shaped MOFs remains almost unexplored, yet is required to overcome intrinsic limitations, such as $\mathrm{CO}_{2}$ adsorption capacity and stability. Here, we present a scalable synthesis method for $\mathrm{Mg}_{2}$ (dobpdc) MOF and its shaped beads, which are obtained by using a spray dry method after mixing $\mathrm{Mg}_{2}$ (dobpdc) powders with alumina sol. The synthesized MOF/Al beads have micron-sized diameters with a moderate particle size distribution of 30-70 $\mu \mathrm{m}$. They also maintain a high mechanical strength. $\mathrm{N}$-ethylethylenediamine (een) functionalization and coating with long alkyl chain silanes results in een-MOF/AI-Si, which exhibits a significant working capacity of $>11 \mathrm{wt} \%$ $\mathrm{CO}_{2}$ capture and high hydrophobicity. The een-MOF/Al-Si microbeads retain their crystallinity and improved $\mathrm{CO}_{2}$ uptake upon exposure to humid conditions for three days at a desorption temperature of $140^{\circ} \mathrm{C}$.

\footnotetext{
${ }^{1}$ Department of Chemistry, Korea University, Seoul 02841, Korea. ${ }^{2}$ Center for Convergent Chemical Process, Korea Research Institute of Chemical Technology, Daejeon 305-600, Korea. ${ }^{凶}$ email: cshong@korea.ac.kr
} 
A fter the industrial revolution, the concentration of $\mathrm{CO}_{2}$ in the atmosphere has been steadily increasing because of the continuous consumption of fossil fuels. This can cause global warming and climate change, and consequently lead to environmental disaster ${ }^{1}$. Carbon capture and sequestration technologies have been implemented to deal with the massive $\mathrm{CO}_{2}$ emissions from coal-fired power plants ${ }^{2-4}$. Among capture technologies, alkanolamine solution scrubbers are one of the most developed systems; however, they are affected by corrosiveness and amine evaporation and have a high energy penalty for regeneration ${ }^{5,6}$. To address these limitations, noncorrosive solid materials with lower heat capacity have attracted considerable attention as alternative adsorbents ${ }^{7-9}$.

Metal-organic frameworks (MOFs) with high surface area and tunable pores have been shown to possess superior $\mathrm{CO}_{2}$ adsorption capacities compared with ordinary solid adsorbents such as zeolites, carbons, and amine-incorporated porous materials ${ }^{10-15}$. In particular, expanded MOF-74 type frameworks, $\mathrm{M}_{2}$ (dobpdc) $\left(\mathrm{M}=\mathrm{Mg}, \mathrm{Mn}, \mathrm{Fe}, \mathrm{Co}, \mathrm{Ni}, \mathrm{Zn}\right.$; dobpdc ${ }^{4-}=$ 4,4'-dioxidobiphenyl-3, $3^{\prime}$-dicarboxylate), exhibit exceptional $\mathrm{CO}_{2}$ adsorption performances because of their high-density open metal sites that are functionalized by diamines, alcoholamines, and alkoxyalkylamines ${ }^{16-21}$. Among the series, diamine-functionalized $\mathrm{Mg}_{2}$ (dobpdc) with record-high adsorption capacities has been proven to be one of the most promising adsorbents for the post-combustion $\mathrm{CO}_{2}$ capture process, while the shape of the isotherm and the ease with which the $\mathrm{CO}_{2}$ can be removed play a much important role from a process point of view 22,23 . Its adsorption and desorption behaviors can be modulated by selecting the appropriate amine structure $^{24-28}$. To improve the structural durability of the MOFs under humidification conditions, cyclic diamines or polyamines have been grafted onto the open metal sites of the $\mathrm{Mg}_{2}$ (dobpdc) platform ${ }^{29,30}$. Coating the platforms with hydrophobic polymers also enhanced the structural stability in the presence of moisture ${ }^{31}$. Currently, diamine-grafted $\mathrm{Mg}_{2}$ (dobpdc) materials are prepared in the powered form, which is not suitable for $\mathrm{CO}_{2}$ capture processes because of disadvantages such as pressure drop, poor reusability and processability. In fact, MOF powders are shaped for practical applications via mechanical shaping including granulation, extrusion, pressing, and spray drying, template shaping including sol-gel method and electrospinning, and other shapings ${ }^{32,33}$. Particularly, spray drying provides a cost-effective, rapid, and scalable method to continuously fabricate the shaped materials ${ }^{34}$. Because diamine-grafted $\mathrm{Mg}_{2}$ (dobpdc) compounds have been extensively explored due to their exceptional $\mathrm{CO}_{2}$ adsorption capacities for post-combustion capture processes ${ }^{16-20,24,25,27-31,35,36}$, shaping of the MOF powders is important to increase their processibility and mechanical strength for real-world $\mathrm{CO}_{2}$ capture applications ${ }^{37,38}$. Furthermore, to overcome the intrinsic limitations of pristine shaped MOFs such as $\mathrm{CO}_{2}$ adsorption capacity and structural stability under humid conditions, their postsynthetic modifications are required but nearly unexplored.

In the present work, we report the scalable synthesis of $\mathrm{Mg}_{2}$ (dobpdc) as well as $\mathrm{Mg}_{2}(\mathrm{dobpdc})$-alumina composite microbeads $(\mathrm{MOF} / \mathrm{Al})$ via the spray-dried shaping of MOF with alumina sol. The attrition index of the beads used was $<0.6 \%$, which meets the desirable mechanical property for the $\mathrm{CO}_{2}$ capture process using solid sorbents. The shaped MOFs were further functionalized by $N$-ethylethylenediamine (een) and then coated by silanes to obtain een-MOF/Al-Si. The postfunctionalized microbeads exhibited a substantial $\mathrm{CO}_{2}$ capacity, $>11 \mathrm{wt} \%$, and improved long-term material stability under humid conditions.

\section{Results and discussion}

Synthesis and characterizations of MOF/Al microbeads. The dimethylformamide (DMF)-coordinated $\mathrm{Mg}_{2}$ (dobpdc) was synthesized by $\mathrm{H}_{4}$ dobpdc and $\mathrm{MgCl}_{2} \cdot 6 \mathrm{H}_{2} \mathrm{O}$ in DMF/EtOH under a solvothermal reaction using a $300 \mathrm{~mL}$ reactor. We also successfully employed a $35 \mathrm{~L}$ steel bomb reactor to produce the analytically pure solid product in a $\mathrm{kg}$ scale. This was used for the MOF shaping. The $\mathrm{Mg}_{2}$ (dobpdc) sample was characterized by powder X-ray diffraction (PXRD), $\mathrm{N}_{2}$ isotherms, and scanning electron microscopy (SEM) (for PXRD, $\mathrm{N}_{2}$ isotherms, and SEM see Supplementary Fig. 1). Fully dried $\mathrm{Mg}_{2}$ (dobpdc) rod-shaped particles were ground to ensure the uniform distribution of the particles. The ground sample was mixed with $10 \mathrm{wt} \%$ alumina sol as a binder and was further treated with the ball-milling process for 30 min to obtain an aqueous slurry. The slurry of $\mathrm{Mg}_{2}$ (dobpdc) with alumina sol was injected into a spray drier to obtain DMF-MOF/ $\mathrm{Al}$ spherical beads in the particle size range $30-70 \mu \mathrm{m}$ (Fig. 1 and for SEM image see Supplementary Fig. 2). The SEM images and SEM-energy dispersive X-ray spectroscopy (SEM-EDS) data exhibited that the MOF rods and alumina particles were well distributed over the surface and the interior of the DMF-MOF/Al bead (Fig. 2c-f and for SEM-EDS mapping see Supplementary Fig. 3). The PXRD data revealed that the structure of the DMF-MOF/Al beads was consistent with that of $\mathrm{Mg}_{2}$ (dobpdc) (Fig. 2a and for PXRD see Supplementary Fig. 4). The infrared (IR) spectrum of the DMF-MOF/Al sample showed additional
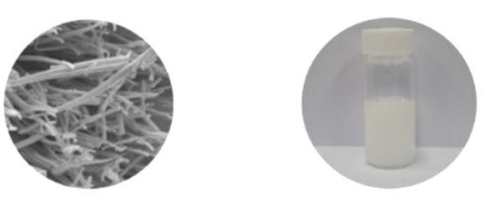

(a) $\rightarrow \mathrm{Mg}_{2}$ (dobpdc)

Alummina sol (=MOF)

(b)

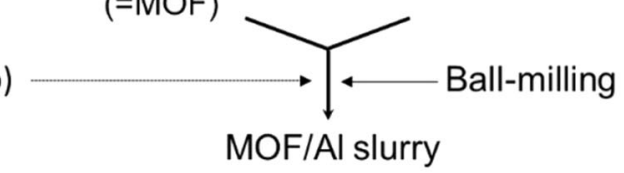

(c)
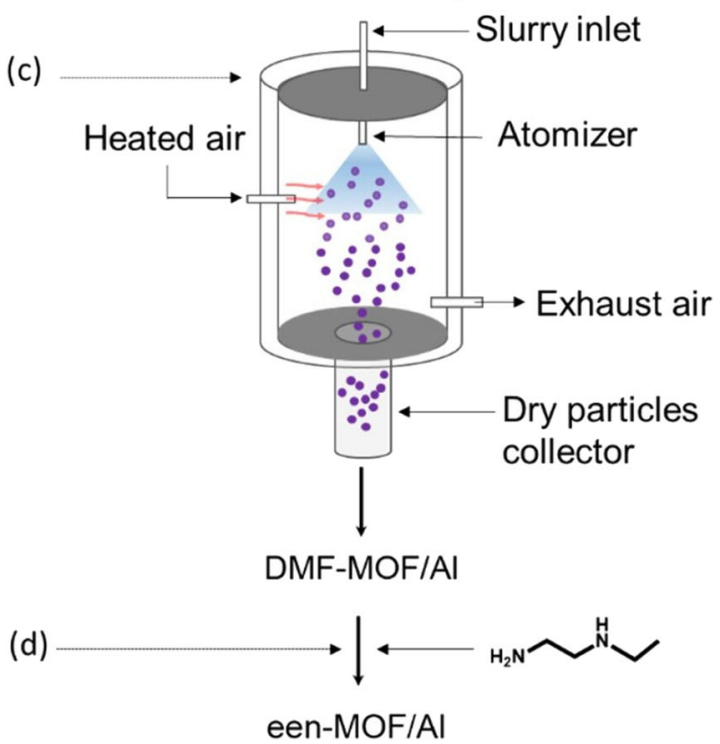

Fig. 1 Schematic of the spray-drying process of MOF/Al microbeads. a Scale-up synthesis of $\mathrm{Mg}_{2}$ (dobpdc) using $300 \mathrm{~mL}$ and $35 \mathrm{~L}$ steel bomb reactors. b Mixing $\mathrm{Mg}_{2}$ (dobpdc) and alumina sol binders through a ballmilling process. c Shaping of MOF/Al microbeads via spray dry method. d Functionalization of MOF/AI microbeads by $\mathrm{N}$-ethylethylenediamine (een). 


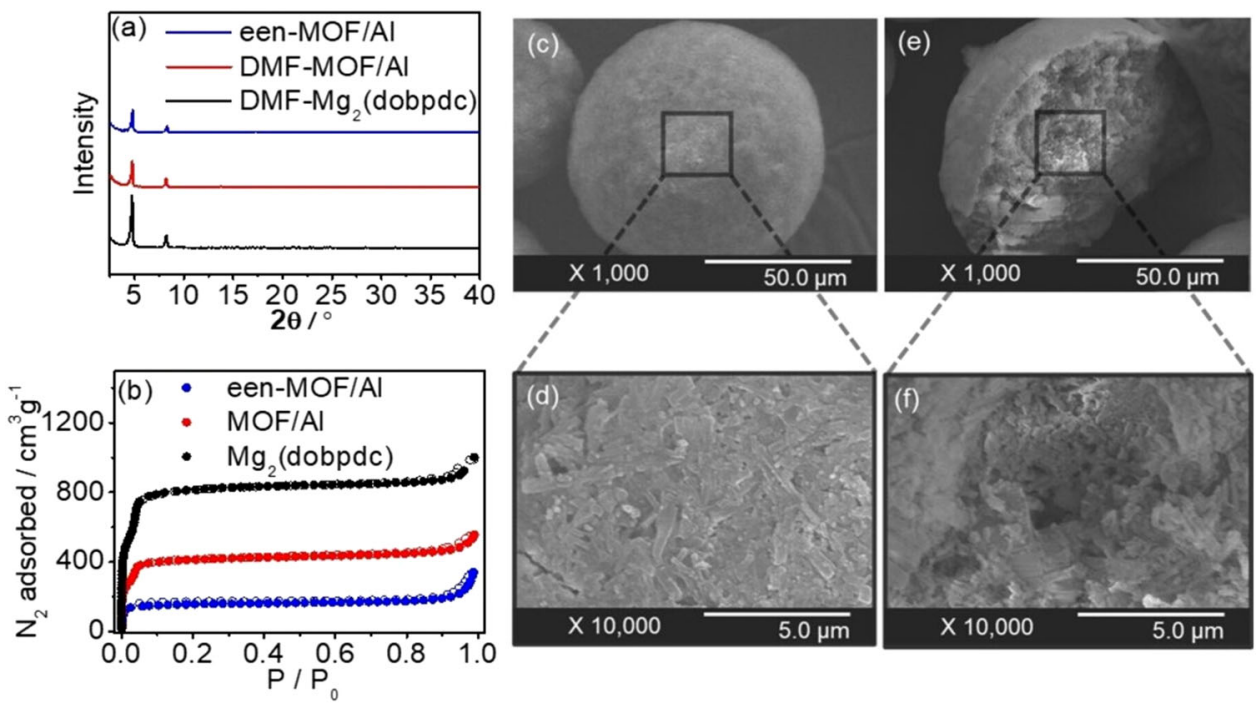

Fig. 2 Characterizations of MOF/Al microbeads and diamine-grafted MOF/Al microbeads. a PXRD data of DMF-MOF, DMF-MOF/Al, and een-MOF/ Al. $\mathbf{b} \mathrm{N}_{2}$ isotherms for $\mathrm{Mg}_{2}$ (dobpdc), MOF/Al, and een-MOF/Al at $77 \mathrm{~K}$. c SEM image of the surface of DMF-MOF/Al. d Enlarged SEM image of the surface of DMF-MOF/AI. e SEM image of the inside of MOF-MOF/Al. $\mathbf{f}$ Enlarged SEM image of the inside of DMF-MOF/Al.

peaks at $1070 \mathrm{~cm}^{-1}$, which are characteristic of Al-O stretching, and at 3330 and $3100 \mathrm{~cm}^{-1}$, which are attributed to $\mathrm{O}-\mathrm{H}$ stretching. This indicates the existence of alumina in the bead (for IR spectra see Supplementary Fig. 5). ICP-AES analysis revealed that the ratio of $\mathrm{Mg}$ to $\mathrm{Al}$ in the DMF-MOF/Al was 1:0.363 (for ICP-AES results see Supplementary Table 1). The binding energies of $\mathrm{Al} 2 \mathrm{p}$ and $2 \mathrm{~s}$ orbitals in the XPS data of the DMF-MOF/Al beads also indicated the successful incorporation of the alumina binder into the spherical bead (for XPS data see Supplementary Fig. 6) ${ }^{39}$. For practical applications, the shaped material should have the appropriate mechanical strength because the collisions of the beads with each other and the surface of the adsorption bed during the capture process will break the shaped particles into the powdered form. An attrition test was conducted to examine the mechanical properties of the microbeads. The attrition index was determined to be $\sim 0.6 \%$, indicating that alumina-bound spheres are sufficiently robust for application in the $\mathrm{CO}_{2}$ capture process ${ }^{40,41}$.

To confirm the porous properties of DMF-MOF/Al beads, $\mathrm{N}_{2}$ sorption was recorded at $77 \mathrm{~K}$. The Brunauer-Emmett-Teller surface areas of $\mathrm{Mg}_{2}$ (dobpdc) and MOF/Al were 3178 and $1656 \mathrm{~m}^{2} \mathrm{~g}^{-1}$, respectively (Fig. $2 \mathrm{~b}$ and for porous properties see Supplementary Table 2). The reduction in the surface area of $\mathrm{MOF} / \mathrm{Al}$ indicates that the pore channel is partially blocked by the alumina binders. This is supported by the decreased pore volume and the unchanged pore channel size (for pore size distribution see Supplementary Fig. 7).

Preparation and characterizations of diamine-grafted MOF/Al microbeads. The functionalization of $\mathrm{Mg}_{2}$ (dobpdc) with diverse diamines enhances $\mathrm{CO}_{2}$ adsorption characteristics that are suitable for post-combustion $\mathrm{CO}_{2}$ capture applications ${ }^{35}$. To increase the $\mathrm{CO}_{2}$ uptake, we grafted $\mathrm{MOF} / \mathrm{Al}$ with $\mathrm{N}$-ethylethylenediamine (een). Before the functionalization of een, $\mathrm{DMF}-\mathrm{MOF} / \mathrm{Al}$ was soaked in $\mathrm{MeOH}$ for 3 days at room temperature to replace the DMF molecules coordinated with the open metal sites with the readily removable $\mathrm{MeOH}$. The absence of the $\mathrm{C}=\mathrm{O}$ stretching vibration of DMF at $1663 \mathrm{~cm}^{-1}$ in the IR spectrum suggests the complete removal of DMF from the bead sample (for IR spectra see Supplementary Fig. 5). The SEM images and XPS data show that the shape and composition of MOF/Al were maintained after $\mathrm{MeOH}$ soaking (for SEM and XPS data see
Supplementary Figs. 2 and 6). We treated the $\mathrm{MeOH}$-soaked sample $(\mathrm{MeOH}-\mathrm{MOF} / \mathrm{Al})$ with 50 equivalents of een in $\mathrm{n}$-hexane for $12 \mathrm{~h}$ at $50{ }^{\circ} \mathrm{C}$ without stirring to obtain an een-functionalized phase, een-MOF/Al. After een grafting, the structure of $\mathrm{Mg}_{2}$ (dobpdc) remained intact, and the morphology of the beads was identical to that of MOF/Al (for SEM image see Supplementary Fig. 2). $\mathrm{N}-\mathrm{H}$ stretching vibration at $3300 \mathrm{~cm}^{-1}$ was observed in the IR spectrum, and the N1s peak was observed at $400 \mathrm{eV}$ in the XPS profile. This indicates the existence of een in the sample (for IR and XPS data see Supplementary Figs. 5 and 6).

From the $\mathrm{N}_{2}$ isotherms of een-MOF/Al, the surface area was calculated as $611 \mathrm{~m}^{2} \mathrm{~g}^{-1}$ (Fig. $2 \mathrm{~b}$ and for surface area see Supplementary Table 2). Because the diamine was grafted onto the open metal sites of the framework, the surface area of een-MOF/Al was smaller than that of $\mathrm{MOF} / \mathrm{Al}$, and its pore size decreased from 18.4 to $14.8 \AA$ (for pore size distribution see Supplementary Fig. 7). The $\mathrm{CO}_{2}$ isotherms of een-MOF/Al had a $\mathrm{CO}_{2}$ uptake of $3.48 \mathrm{mmol} \mathrm{g}^{-1}$ at $150 \mathrm{mbar} \mathrm{CO}_{2}$, which is similar to that of een-MOF (for $\mathrm{CO}_{2}$ isotherms see Supplementary Figs. 8 and 9$)^{28}$. This indicates that using alumina nanoparticles for shaping binds the MOF rods, while keeping the pores open for $\mathrm{CO}_{2}$ diffusion. The $\mathrm{CO}_{2}$ uptake of the sample was negligible at 1 bar $\mathrm{CO}_{2}$ at $140{ }^{\circ} \mathrm{C}$, implying that $\mathrm{CO}_{2}$ can be desorbed even under $100 \% \mathrm{CO}_{2}$ at that temperature. The complete desorption of the adsorbed $\mathrm{CO}_{2}$ is important for the repeated reuse of the adsorbent for real-world post-combustion applications. The step pressure in the isotherms of the MOF beads suggests the mechanism of operation of $\mathrm{CO}_{2}$ insertion, which was observed in diamine-functionalized $\mathrm{Mg}_{2}$ (dobpdc) series ${ }^{35}$. We calculated the isosteric heat of the adsorption $\left(Q_{\text {st }}\right)$ using the dual-site Langmuir-Freundlich (L-F) and Clausius-Clapeyron equations (for isosteric heats of $\mathrm{CO}_{2}$ adsorption see Supplementary Fig. 10). The $-Q_{\text {st }}$ of een-MOF/Al was in the range $69-82 \mathrm{~kJ} \mathrm{~mol}^{-1}$, attributed to the chemisorption.

Introducing hydrophobic silane into the MOF/Al. Flue gas emitted from coal-fired power plants contains 5-7\% water vapor ${ }^{2}$. Hydrophilic materials can readily adsorb water vapors; however, the desorption of the adsorbed water molecules requires high energy input ${ }^{42}$. Thus, a potential adsorbent for $\mathrm{CO}_{2}$ capture should also be hydrophobic to preclude the access of water vapors 

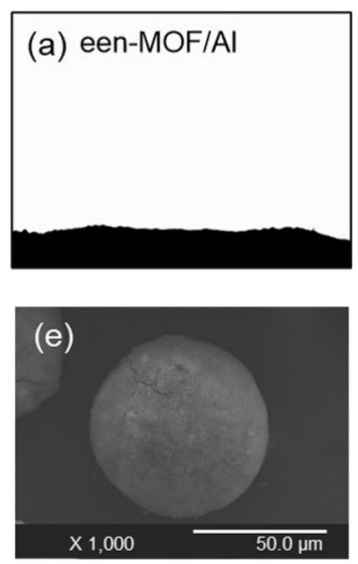

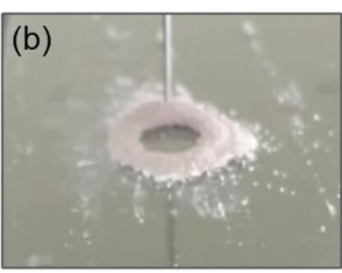

Mg Ka1_2

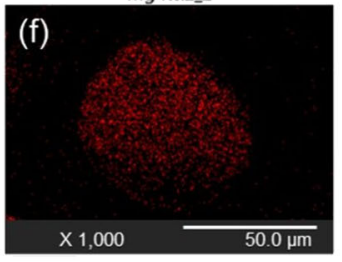

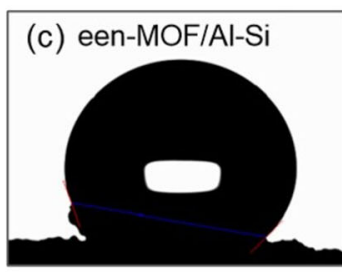

Al Ka1

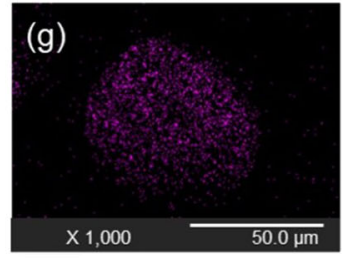

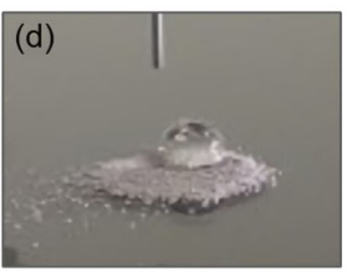

Si $K \alpha 1$

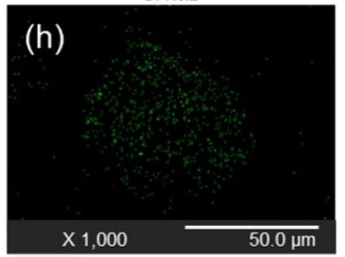

Fig. 3 Characterizations of een-MOF/Al-Si. a Contact angle of een-MOF/Al. b Photograph of een-MOF/AI after dropping water. c Contact angle of een-MOF/AI-Si. d Photograph of een-MOF/AI-Si after dropping water. e SEM image of een-MOF/AI-Si. f-h SEM-EDS mappings of een-MOF/AI-Si.

to the pores of the material. To examine the surface properties of $\mathrm{DMF}-\mathrm{MOF} / \mathrm{Al}$ and een-MOF/Al, we measured the contact angles using a water droplet. No contact angle was observed with $\mathrm{MOF} / \mathrm{Al}$ and een-MOF/Al, indicating that the samples were hydrophilic (Fig. 3a, b and for contact angles see Supplementary Fig. 11). To enhance hydrophobicity, silanes $\mathrm{H}-\left(\mathrm{CH}_{2}\right)_{n}-\mathrm{Si}$ $(\mathrm{OMe})_{3}$ with chains of different numbers of carbon atoms were introduced into the een-MOF/Al beads. When $n=3$, there was no contact angle, and the hydrophilic characteristic remained (for contact angles see Supplementary Fig. 12). By increasing $n$, a high contact angle $\left(>105^{\circ}\right)$ was obtained; however, it disappeared quickly. Remarkably, when octadecyltrimethoxysilane with $n=$ 18 was used to obtain the silane-coated product, een-MOF/Al-Si, a contact angle $>100^{\circ}$ was maintained for $30 \mathrm{~min}$ (Fig. 3c, d). It is clear that a longer carbon chain with silane increases the contact angle of the sample because of the increased bulkiness and hydrophobicity. The PXRD pattern of een-MOF/Al-Si agreed with that of een-MOF/Al, indicating that the MOF structure was well-maintained during the silane coating (for PXRD data see Supplementary Fig. 13). In the IR spectra, the C-H stretching vibrations at 2850 and $2950 \mathrm{~cm}^{-1}$ were assigned to the long carbon chains of the silane moiety (for IR spectra see Supplementary Fig. 14). Both the SEM images and SEM-EDS data showed that the shape of the spherical beads was maintained and that the silanes were well distributed over the surface and interior of een-MOF/Al-Si (Fig. $3 \mathrm{e}-\mathrm{h}$ and for SEM-EDS mapping see Supplementary Fig. 15). This is also corroborated by the XPS results in which $\mathrm{Al}$ and Si peaks were visible (for XPS data see Supplementary Fig. 16). The $\mathrm{N}_{2}$ isotherm of een-MOF/Al-Si at $77 \mathrm{~K}$ exhibited a surface area of $17 \mathrm{~m}^{2} \mathrm{~g}^{-1}$ (for $\mathrm{N}_{2}$ isotherm see Supplementary Fig. 17). The silane coating of een-MOF/Al can obstruct the diffusion of $\mathrm{N}_{2}$ gas by blocking the pore channels with the long carbon chain. This significantly reduces the surface area of een-MOF/Al-Si. Furthermore, the $\mathrm{CO}_{2}$ isotherm was collected at $195 \mathrm{~K}$ (for $\mathrm{CO}_{2}$ isotherm see Supplementary Fig. 18). The isotherm showed that een-MOF/Al-Si adsorbs $\mathrm{CO}_{2}$ at that low temperature. This result suggests that $\mathrm{CO}_{2}$ can be diffused into the MOF channel despite the interference of the long carbon chain on silane, which is due to the smaller size of $\mathrm{CO}_{2}$ than $\mathrm{N}_{2}$.

We supposed that silanes can react with the hydroxy groups on the alumina binders and with the non-coordinating functional groups of the ligands on the surface of MOF in een-MOF/Al via condensation among methoxy, hydroxyl, and carboxylic groups $^{43}$. To prove this hypothesis, we introduced octadecyltrimethoxysilane to een-MOF and alumina under the same conditions applied for bead coating. The silane-coated een-MOF
(een-MOF-Si) and alumina (alumina-Si) showed hydrophobicity with contact angles of $63^{\circ}$ and $141^{\circ}$, respectively (for contact angles see Supplementary Fig. 19). The characteristic peaks were positioned at 2850 and $2950 \mathrm{~cm}^{-1}$ in the IR spectra of silanecoated alumina and een-MOF, which can be assigned to the $\mathrm{C}-\mathrm{H}$ stretchings in silane (for IR spectra see Supplementary Fig. 20). Furthermore, the XPS analysis revealed that $\mathrm{Si}$ peaks were observed in een-MOF-Si and alumina-Si, indicating the presence of silane moiety in the samples (for XPS data see Supplementary Figs. 21 and 22). This demonstrates that the silanes are coated on the alumina surface as well as the MOF surface in een-MOF/ Al-Si.

$\mathrm{CO}_{2}$ adsorption-desorption behaviors of een-MOF/Al and een-MOF/Al-Si. The $\mathrm{CO}_{2}$ adsorption curves were measured at different temperatures to evaluate the $\mathrm{CO}_{2}$ adsorption performance of een-MOF/Al-Si (Fig. 4a). The $\mathrm{CO}_{2}$ uptake was 3.15 mmol $\mathrm{g}^{-1}$ at $150 \mathrm{mbar}$, which is still significant and only slightly lower than that of een-MOF/Al. The step pressure implies that the $\mathrm{CO}_{2}$ insertion mechanism is operative even after the introduction of silane. For een-MOF/Al-Si, the step moved to a higher pressure because long carbon chains on silane slightly disturb $\mathrm{CO}_{2}$ diffusion into the MOF channel at low partial $\mathrm{CO}_{2}$ pressures (for $\mathrm{CO}_{2}$ isotherms see Supplementary Fig. 9). To confirm a selectivity of $\mathrm{CO}_{2} / \mathrm{N}_{2}, \mathrm{~N}_{2}$ isotherms were obtained at the same temperature ranges as the $\mathrm{CO}_{2}$ isotherms (for $\mathrm{N}_{2}$ isotherms see Supplementary Fig. 23). We calculated the selectivity using formula, $S=\left(q_{\mathrm{CO}_{2}} / q_{\mathrm{N}_{2}}\right) /\left(P_{\mathrm{Co}_{2}} / P_{\mathrm{N}_{2}}\right)$, where $q_{i}$ and $p_{i}$ are the adsorption capacity and the partial pressure, respectively, of component $i$. The selectivity at $15 \% \mathrm{CO}_{2}$ and $75 \% \mathrm{~N}_{2}$ corresponded to 53,182 at $40{ }^{\circ} \mathrm{C}, 1260$ at $60^{\circ} \mathrm{C}, 595$ at $80^{\circ} \mathrm{C}, 523$ at $100{ }^{\circ} \mathrm{C}, 5$ at $120^{\circ} \mathrm{C}$, and 3 at $140{ }^{\circ} \mathrm{C}$ (for selectivity see Supplementary Table 3). The tendency shows that the selectivity decreased as the temperature increased. The selectivity of 595 at the adsorption temperature of $80^{\circ} \mathrm{C}$ indicates that the presence of $\mathrm{N}_{2}$ could be ignorable during adsorption of $\mathrm{CO}_{2}$. The calculated $Q_{\text {st }}$ of een-MOF/Al-Si was in the range $71-73 \mathrm{~kJ} \mathrm{~mol}^{-1}$, which is similar to that of een-MOF/Al (for isosteric heats of $\mathrm{CO}_{2}$ adsorption see Supplementary Fig. 10). For een-MOF/Al-Si, we observed the change in $\Delta T=T_{\text {des }}-T_{\text {ads }}$ with the adsorption temperature $\left(T_{\mathrm{ads}}\right)$ at the desorption temperature $\left(T_{\mathrm{des}}\right)$ of 130 and $140{ }^{\circ} \mathrm{C}$, respectively, under 2.5 and $15 \% \mathrm{CO}_{2}$ (for correlation diagram see Supplementary Fig. 24). At $T_{\text {des }}=140{ }^{\circ} \mathrm{C}$, the working capacity increased from 11.1 to $12.6 \mathrm{wt} \%$, even under a low pressure of $2.5 \% \mathrm{CO}_{2}$ as $\Delta T$ increased from 50 to $100^{\circ} \mathrm{C}$. The 

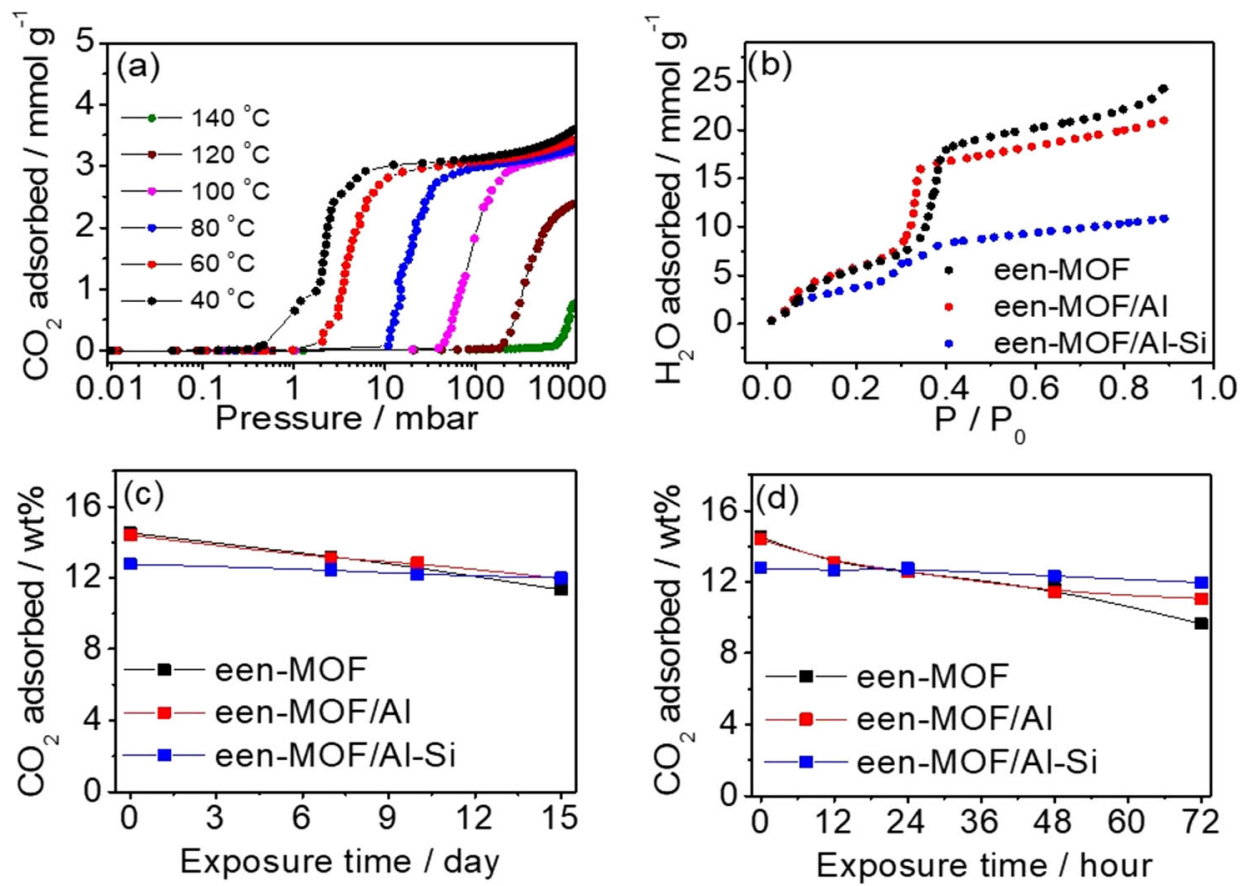

Fig. 4 Gas sorption behaviors and long-term stability test under humid condition. a Adsorption isotherms of $\mathrm{CO}_{2}$ for een-MOF/Al-Si at various temperatures. b Water vapor isotherms of een-MOF, een-MOF/Al, and een-MOF/Al-Si. c $\mathrm{CO}_{2}$ adsorption capacity of een-MOF, een-MOF/Al, and een-MOF/AI-Si after exposure to ambient air by using TGA. $\mathbf{d ~ C O} \mathrm{CO}_{2}$ adsorption capacity of een-MOF, een-MOF/Al, and een-MOF/AI-Si after exposure to $10 \% \mathrm{H}_{2} \mathrm{O}$ and $90 \% \mathrm{CO}_{2}$ at $140{ }^{\circ} \mathrm{C}$ by using TGA. The flow rate was $50 \mathrm{cc} \mathrm{min}^{-1}$.

observed working capacity was in the upper bound of the $\mathrm{CO}_{2}$ capacity observed for solid adsorbents 7,35 . We investigated the adsorption capacities of een-MOF/Al-Si using Thermogravimetric analyses (TGA) at different $\mathrm{CO}_{2}$ concentrations and temperatures as a function of time (for adsorption capacities see Supplementary Fig. 25). To display adsorption rate clearly, we differentiated $\mathrm{CO}_{2}$ uptake curve with respect to time (for adsorption rate see Supplementary Fig. 26). From the differentiated data, $\mathrm{CO}_{2}$ adsorption rate increased as the $\mathrm{CO}_{2}$ partial pressure increased and the temperature decreased. For example, adsorption rates at $40^{\circ} \mathrm{C}$ changed from $4.57 \mathrm{wt} \% \mathrm{~min}^{-1}$ at $2.5 \%$ $\mathrm{CO}_{2}$ to $22.6 \mathrm{wt} \% \mathrm{~min}^{-1}$ at $15 \% \mathrm{CO}_{2}$ to $53.72 \mathrm{wt} \% \mathrm{~min}^{-1}$ at $100 \%$ $\mathrm{CO}_{2}$. At $15 \% \mathrm{CO}_{2}$, the adsorption rate of $22.61 \mathrm{wt} \% \mathrm{~min}^{-1}$ at $40{ }^{\circ} \mathrm{C}$ was significantly reduced to $0.15 \mathrm{wt} \% \mathrm{~min}^{-1}$ at $140{ }^{\circ} \mathrm{C}$. These results unveiled that een-MOF/Al-Si has a high adsorption rate even in the form of beads $28,36,44$. We also performed temperature swing adsorption (TSA) cycle tests of een-MOF/Al-Si to evaluate the reusability (for TSA cycles see Supplementary Fig. 27). Adsorption was conducted at $15 \% \mathrm{CO}_{2}$ and $80^{\circ} \mathrm{C}$ for 5 min and desorption took place at $100 \% \mathrm{CO}_{2}$ and $140^{\circ} \mathrm{C}$ for 1 min. After 100 cycles, the adsorption amount of een-MOF/Al-Si was maintained without a capacity loss. Thus, een-MOF/Al-Si is a promising adsorbent with high working capacity, high adsorption rate, and reusability.

$\mathrm{CO}_{2}$ adsorption mechanisms of een-MOF/Al and een-MOF/ Al-Si. To examine the $\mathrm{CO}_{2}$ adsorption mechanism of een-MOF/ $\mathrm{Al}$ and een-MOF/Al-Si, we performed in situ IR spectroscopy under $\mathrm{CO}_{2}$ and plotted the results as a function of time (for IR spectra see Supplementary Figs. 28 and 29). The samples were activated at $140^{\circ} \mathrm{C}$ for $2 \mathrm{~h}$ under $\mathrm{N}_{2}$ and then exposed to a stream of $100 \% \mathrm{CO}_{2}$ at $40{ }^{\circ} \mathrm{C}$. For both samples, new peaks emerged at $3429,3408,1651$, and $1319 \mathrm{~cm}^{-1}$ after exposure for $1 \mathrm{~min}$. The first two peaks ( 3429 and $3408 \mathrm{~cm}^{-1}$ ) were attributed to the $\mathrm{N}-\mathrm{H}$ stretchings, and the other two $\left(1651\right.$ and $\left.1319 \mathrm{~cm}^{-1}\right)$ were assigned to $\mathrm{C}-\mathrm{O}$ and $\mathrm{C}-\mathrm{N}$ vibrations, respectively. This reveals that carbamate species $\left(\mathrm{R}-\mathrm{NH}-\mathrm{CO}_{2}{ }^{-}\right.$) is generated in een-MOF/ $\mathrm{Al}$ and een-MOF/Al-Si, which is in good agreement with the $\mathrm{CO}_{2}$ insertion mechanism observed in diamine-functionalized $\mathrm{Mg}_{2}$ (dobpdc) frameworks ${ }^{17,28}$. Furthermore, we acquired the solid-state ${ }^{13} \mathrm{C}$ NMR spectra of een-MOF/Al and een-MOF/ $\mathrm{Al}-\mathrm{Si}$ before and after $\mathrm{CO}_{2}$ uptake. In the spectra of een-MOF/ $\mathrm{Al}-\mathrm{Si}$, the carbons on een were observed in the range $35-56 \mathrm{ppm}$, carbons on octadecylsilane at $31 \mathrm{ppm}$, benzene carbons of dobpdc $^{4-}$ in the range $120-133 \mathrm{ppm}$, benzene carbon adjacent to oxygen at $167 \mathrm{ppm}$, and carboxylate carbon at $174 \mathrm{ppm}$. After $\mathrm{CO}_{2}$ adsorption, the positions of the carbons in the carboxylate group and een groups changed slightly, indicating that these groups were affected by $\mathrm{CO}_{2}$ insertion due to the proximity to the insertion site. Moreover, a new peak appeared at $163 \mathrm{ppm}$, which is attributed to the carbamate carbon generated after $\mathrm{CO}_{2}$ adsorption (for solid-state ${ }^{13} \mathrm{C}$ NMR spectra see Supplementary Fig. 30 ${ }^{45}$. Meanwhile, the peaks related to the carbons of the silane were mostly unchanged, suggesting that the silane does not affect the $\mathrm{CO}_{2}$ adsorption mechanism. In the solid-state ${ }^{15} \mathrm{~N}$ NMR spectra of een-MOF/Al and een-MOF/Al-Si, two peaks were observed at 15.1 and $33.7 \mathrm{ppm}$; these were assigned to the two nitrogen atoms of een. After $\mathrm{CO}_{2}$ uptake, the peaks shifted to 40.3 and $74.6 \mathrm{ppm}$, corresponding to ammonium and carbamate nitrogen atoms, respectively. The nuclear magnetic resonance (NMR) results revealed that the adsorption mechanism involves even after the MOF shaping and silane coating (for solid-state ${ }^{15} \mathrm{~N}$ NMR spectra see Supplementary Fig. 31 ).

Long-term stability test under humid conditions. The water vapor isotherms of een-MOF, een-MOF/Al, and een-MOF/Al-Si were collected at $25^{\circ} \mathrm{C}$ (Fig. 4b). The water uptake of een-MOF/ $\mathrm{Al}-\mathrm{Si}$ was lower than that of een-MOF and een-MOF/Al, indicating that the silane coating makes the material more hydrophobic by impeding the access of water molecules. To examine the effect of coating on the structural stability and $\mathrm{CO}_{2}$ 
performance $^{31}$, we exposed the samples to ambient air for 15 days. The $\mathrm{CO}_{2}$ adsorption amount decreased almost linearly for een-MOF and een-MOF/Al as the exposure time increased, reaching $83 \%(11.33 \mathrm{wt} \%)$ and $78 \%(11.95 \mathrm{wt} \%)$ of the initial capacity, respectively. In contrast, for the silane-coated een-MOF/Al-Si, the $\mathrm{CO}_{2}$ uptake remained almost constant with maintaining a capacity of $>12 \mathrm{wt} \%$ after exposure for 15 days (Fig. 4c). The PXRD data revealed that the silane-coated sample retained its structural integrity, while the structures of the other samples partially collapsed (for PXRD data see Supplementary Fig. 32). To further investigate the material's stability in the presence of water vapor, we exposed it to harsh conditions of $10 \%$ $\mathrm{H}_{2} \mathrm{O}$ and $90 \% \mathrm{CO}_{2}$ at a desorption temperature of $140^{\circ} \mathrm{C}$, which are more practical environments for real-world post-combustion $\mathrm{CO}_{2}$ capture applications (Fig. $4 \mathrm{~d}$ ). The adsorption capacity of een-MOF/Al linearly decreased to $76 \%(11.07 \mathrm{wt} \%)$ of the original capacity after 3 days. The capacity loss was due to the structural collapse (for PXRD data see Supplementary Fig. 33). It is noted that the capacity of een-MOF/Al-Si was almost retained with a capacity of $\sim 12 \mathrm{wt} \%$ after 3 days of exposure (Fig. $4 \mathrm{~d}$ ). This result demonstrates that the silane coating significantly enhances structural stability and performance durability (for $\mathrm{CO}_{2}$ adsorption capacities see Supplementary Fig. 33).

Furthermore, to investigate $\mathrm{CO}_{2}$ adsorption in the presence of water vapor, we collected $\mathrm{CO}_{2}$ uptake at dry conditions of $80^{\circ} \mathrm{C}$ under $15 \% \mathrm{CO}_{2}, 85 \% \mathrm{He}$, and a flow rate of $10 \mathrm{cc} \mathrm{min}^{-1}$. The $\mathrm{CO}_{2}$ adsorption was recorded at wet conditions of $80^{\circ} \mathrm{C}$ under $15 \% \mathrm{CO}_{2}, 3.75 \% \mathrm{H}_{2} \mathrm{O}, 81.25 \% \mathrm{He}$, and a flow rate of $10 \mathrm{cc} \mathrm{min}{ }^{-1}$. The water vapor was generated from a bubbler and was removed at a trap after passing through the sample before reaching the thermal conductivity detector (TCD). The $\mathrm{CO}_{2}$ adsorption capacity and rate for een-MOF/Al-Si were similar to those of TGA results. The amount of $\mathrm{CO}_{2}$ uptake was $10.24 \mathrm{wt} \%$ in the dry conditions and $10.88 \mathrm{wt} \%$ in the wet conditions. The $\mathrm{CO}_{2}$ adsorption capacity was a little higher at wet conditions than dry conditions, which was commonly observed in diamine-grafted $\mathrm{Mg}_{2}$ (dobpdc) frameworks $24,28,31$. Thus, een-MOF/Al-Si can selectively adsorb $\mathrm{CO}_{2}$ even in the presence of water vapor.

Since amines can be degraded in the presence of $\mathrm{O}_{2}$ from the flue gas, potential adsorbents are required to be stable under $\mathrm{O}_{2}{ }^{12,13}$. To confirm the $\mathrm{O}_{2}$ stability of een-MOF/Al-Si, adsorption were carried out under a mixed gas of $15 \% \mathrm{CO}_{2}$ and $5 \% \mathrm{O}_{2}$ and at $80{ }^{\circ} \mathrm{C}$ for $5 \mathrm{~min}$, while desorption occurred at $100 \% \mathrm{CO}_{2}$ and $140{ }^{\circ} \mathrm{C}$ for $1 \mathrm{~min}$ (for TSA cycles see Supplementary Fig. 35). After 50 cycles, it was confirmed the $\mathrm{CO}_{2}$ adsorption capacity was almost maintained at $9.52 \mathrm{wt} \%$ when compared to $9.96 \mathrm{wt} \%$ in the first cycle.

\section{Conclusion}

We demonstrated the scalable synthesis of $\mathrm{Mg}_{2}$ (dobpdc) as well as shaped MOF microbeads via a spray dry method. The microbeads exhibited excellent mechanical properties, which are important for practical applications. We also performed the sequential postsynthetic functionalizations such as diamine grafting and silane coating of the beads to obtain a hydrophobic material with a significant working capacity and enhanced structural stability under humid conditions. The postfunctionalized MOF microbead materials with the remarkable long-term performance can be applied as adsorbents in realworld $\mathrm{CO}_{2}$ capture processes.

\footnotetext{
Methods

Preparation. $\mathrm{H}_{4}$ dobpdc was synthesized according to the previous literature ${ }^{16}$ $\mathrm{MgCl}_{2} \cdot 6 \mathrm{H}_{2} \mathrm{O}(\geq 98.0 \%), \mathrm{N}$-ethylethylenediamine (een, $\left.\geq 98.0 \%\right)$ and octadecyltrimethoxysilane were obtained from Sigma-Aldrich. All solvents were reagent
}

grade $(\geq 99.0 \%)$ and used as received. Alumina sol $(10 \mathrm{wt} \%, \mathrm{pH}=4$, particle size $=$ 10-20 nm) was purchased from Alutec company.

Synthesis of $\mathrm{Mg}_{2}$ (dobpdc) in a $\mathrm{g}$ scale. $\mathrm{Mg}_{2}$ (dobpdc) was synthesized through a previous synthesis method, and synthesized through a $300 \mathrm{~mL}$ high-pressure reactor. $\mathrm{MgCl}_{2} \cdot 6 \mathrm{H}_{2} \mathrm{O}(19.7 \mathrm{~g}, 970 \mathrm{mmol})$ was dissolved in $\mathrm{EtOH}(100 \mathrm{~mL})$ and $\mathrm{H}_{4}$ dobpdc (7.60 g, $\left.277 \mathrm{mmol}\right)$ was dissolved in DMF $(100 \mathrm{~mL})$. The resulting solutions were poured into a $300 \mathrm{~mL}$ autoclave. The mixture was reacted for $72 \mathrm{~h}$ at $130^{\circ} \mathrm{C}$. After the reaction, the resulting powder was separated via filtration and soaked in DMF.

Synthesis of $\mathrm{Mg}_{2}$ (dobpdc) in a $\mathrm{kg}$ scale. Scale-up $\mathrm{Mg}_{2}$ (dobpdc) was synthesized in the following method. $\mathrm{MgCl}_{2} \cdot 6 \mathrm{H}_{2} \mathrm{O}(1.50 \mathrm{~kg}, 7.29 \mathrm{~mol})$ was dissolved in $\mathrm{EtOH}$ $(10.0 \mathrm{~L})$ and $\mathrm{H}_{4}$ dobpdc $(1.00 \mathrm{~kg}, 3.64 \mathrm{~mol})$ was dissolved in DMF $(10.0 \mathrm{~L})$. The resulting solutions were poured into a $35 \mathrm{~L}$ autoclave. The mixture was reacted for $72 \mathrm{~h}$ at $140{ }^{\circ} \mathrm{C}$. After the reaction, the resulting powder was separated via filtration and soaked in mother liquid.

Synthesis of $\mathrm{Mg}_{2}($ dobpdc)/alumina beads (DMF-MOF/Al). DMF-MOF/Al was manufactured in the following method. DMF-MOF was dried in an oven for $24 \mathrm{~h}$ at $100{ }^{\circ} \mathrm{C}$. The resultant sample $(100 \mathrm{~g})$ was grounded with water $(340 \mathrm{~mL})$ and alumina sol (111 g, alumina content $10 \mathrm{wt} \%)$ using $3 \mathrm{~mm} \mathrm{ZrO}_{2}$ ball $(130 \mathrm{~g})$ in a ball-mill instrument for $30 \mathrm{~min}$ under $300 \mathrm{rpm}$. After grinding, the obtained MOF/ $\mathrm{Al}$ slurry was injected into a spray drier using a feeding machine. The MOF/Al slurry, which passed through the atomizer, was formed into spherical particles. When the high-temperature gas was blown to the spherical particles, it hardened immediately (input gas temperature $=290^{\circ} \mathrm{C}$, output gas temperature $=130{ }^{\circ} \mathrm{C}$ ). The dried particles were collected in a dry particle collector to yield DMF-MOF/Al beads (58 g).

Synthesis of een- $\mathrm{Mg}_{2}($ dobpdc)/alumina beads (een-MOF/Al). DMF-MOF/Al was soaked in $\mathrm{MeOH}$ for $72 \mathrm{~h}$ and refreshed everyday with $\mathrm{MeOH}$. The $\mathrm{MeOH}$-soaked sample was placed in a $100-\mathrm{mL}$ Schlenk flask and dried for $24 \mathrm{~h}$ at $150{ }^{\circ} \mathrm{C}$ under vacuum. The dried sample $(300 \mathrm{mg}, 0.78 \mathrm{mmol})$ was replaced in a $100-\mathrm{mL}$ oneneck round flask. $N$-ethylethylenediamine $(4.12 \mathrm{~mL}, 39.1 \mathrm{mmol})$ and hexane $(20 \mathrm{~mL})$ were put into the flask using cannula. The mixture was soaked for $12 \mathrm{~h}$ at $50^{\circ} \mathrm{C}$. After the reaction, the mixture was filtered and washed with hexane. Light purple products were dried under vacuum for $2 \mathrm{~h}$.

Synthesis of een- $\mathrm{Mg}_{2}($ dobpdc)/alumina-silane beads (een-MOF/Al-Si). Dried een-MOF/Al (300 mg) was placed in a $100-\mathrm{mL}$ one-neck round flask. Octadecyltrimethoxysilane $(1.5 \mathrm{~g})$ and hexane $(40 \mathrm{~mL})$ were poured into the flask. The mixture was soaked for $72 \mathrm{~h}$ at $50^{\circ} \mathrm{C}$. After the reaction, the mixture was filtered and washed three times with hexane. Gray products were dried under vacuum for $2 \mathrm{~h}$.

Synthesis of een-MOF-Si and alumina-Si. een-MOF-Si was synthesized in the following method. Dried een-MOF $(300 \mathrm{mg})$ was placed in a $100-\mathrm{mL}$ one-neck round flask. Octadecyltrimethoxysilane $(1.5 \mathrm{~g})$ and hexane $(40 \mathrm{~mL})$ were put into the flask. The mixture was soaked for $72 \mathrm{~h}$ at $50^{\circ} \mathrm{C}$. After the reaction, the mixture was filtered and then soaked in fresh hexane for 3 days in order to eliminate unreacted octadecylsilane. After 3 days, een-MOF-Si was collected by filtration. Alumina-Si was synthesized in the similar reaction using alumina. After heating of alumina sol at $100{ }^{\circ} \mathrm{C}$ for $6 \mathrm{~h}$ under vacuum, alumina in a solid state was obtained. Obtained alumina was grounded by a mortar to make fine powders. Ground alumina $(300 \mathrm{mg})$ was placed in a $100-\mathrm{mL}$ one-neck round flask. Octadecyltrimethoxysilane $(1.5 \mathrm{~g})$ and hexane $(40 \mathrm{~mL})$ were put into the flask. The mixture was soaked for $72 \mathrm{~h}$ at $50^{\circ} \mathrm{C}$. After the reaction, the mixture was filtered and then soaked in fresh hexane for 3 days in order to eliminate unreacted octadecylsilane. After 3 days, alumina-Si was collected by filtration.

Physical measurements. PXRD patterns were recorded using $\mathrm{Cu}$ Ka radiation $(\lambda=1.5406 \AA)$ with a Rigaku Ultima III diffractometer with a scan rate of $2^{\circ} \mathrm{min}^{-1}$ and a step interval of $0.02^{\circ}$. Contact angle was measured by Phoenix-MT(T). X-ray photoelectron spectroscopy (XPS, K-Alpha ${ }^{+}$) data were taken at Hanyang University. SEM images were collected using S-4600 at Korea Basic Science Institute (KBSI).

Attrition test. Attrition test was carried out by a crafted device at Korea Research Institute of Chemical Technology based on ASTM D5757 standard method ${ }^{46}$. This device is composed of distributor, attrition tube, setting chamber, and fine collection assembly. The distributor and attrition tube have a tube with $35 \mathrm{~mm}$ inside diameter, $710 \mathrm{~mm}$ in length, and three $0.397 \mathrm{~mm}$ holes on the distributor. The attrition tube is linked to a setting chamber and a fines collector. The sample was injected to the distributor by blowing air in a rate of $10 \mathrm{~L} \mathrm{~min}^{-1}$. The sample that was passed through the three holes on the distributor collided with each other in the attrition tube. The crashed sample in the attrition tube was transferred to the setting chamber, and the finely ground sample was transported through the internal filter of the chamber to the fines collector. This process was performed for 
$5 \mathrm{~h}$ under dry air. The attrition index was calculated by following formula: Attrition index $(\mathrm{AI})=\frac{\text { Weight of collected sample on fine collection assembly }}{\text { Weight of initial sample }} \times 100$

Gas adsorption measurements. Gas sorptions with $\mathrm{CO}_{2}$ (99.999\%) and $\mathrm{N}_{2}$ (99.999\%) were performed using a Micromeritics 3flex instrument after the pretreatment of each sample. Density functional theory pore size distributions for $\mathrm{Mg}_{2}$ (dobpdc) (MOF), MOF/Al, een-MOF/Al, and een-MOF/Al-Si were estimated from $\mathrm{N}_{2}$ isotherms at $77 \mathrm{~K}$ using the model of cylindrical pores with oxide surface. The water vapor isotherms were recorded by ASAP 2020 instrument after the treatment of samples at $298 \mathrm{~K}$. To investigate the $\mathrm{CO}_{2}$ adsorption capacity in the presence of water vapor, we used modified temperature-programed desorption (TPD) processes in the BELCAT-II instrument. We obtained TCD signals for $\mathrm{CO}_{2}$ under dry and wet conditions during TPD processes and quantized the amount of $\mathrm{CO}_{2}$ uptake versus time through the area of TPD signals for $\mathrm{CO}_{2}$.

\section{Thermogravimetric analyses and water vapor exposure test. TGA were} obtained at a ramp speed of $20^{\circ} \mathrm{C} \mathrm{min}^{-1}$ in a stream of $15 \% \mathrm{CO}_{2}$ and $100 \% \mathrm{CO}_{2}$ using a TA instrument Discovery TGA with a flow rate of $70 \mathrm{~mL} \mathrm{~min}^{-1}$ for all gases. The water vapor exposure test was conducted by a homemade setup. The water vapor (about $10 \% \mathrm{H}_{2} \mathrm{O}$ ) was formed from a round-bottomed flask in which water was warmed at $50^{\circ} \mathrm{C} . \mathrm{CO}_{2}(99.999 \%)$ gas was flowed through the flask and then passed into the sample chamber heated at $140^{\circ} \mathrm{C}$. After exposure test, the samples were recollected to measure adsorption capacity using a TGA instrument under $15 \% \mathrm{CO}_{2}$ for 30 min after activation under $\mathrm{N}_{2}$ atmosphere.

Exposure tests. For air exposure, each sample $(100 \mathrm{mg}$ ) was put into a $20 \mathrm{~mL}$ vial and exposed to an ambient air. Then, we measured adsorption uptake of the sample using a TGA instrument at $15 \% \mathrm{CO}_{2}$ for 30 min after activation under $\mathrm{N}_{2}$. For humidity exposure, water vapor (about $10 \% \mathrm{H}_{2} \mathrm{O}$ ) was generated from a round-bottomed flask by warming water at $50{ }^{\circ} \mathrm{C} . \mathrm{CO}_{2}(99.999 \%)$ was passed through the flask and then injected into a homemade sample chamber heated at $140^{\circ} \mathrm{C}$. After the exposure tests, samples were recollected to measure adsorption capacity using a TGA instrument under $15 \% \mathrm{CO}_{2}$ for $30 \mathrm{~min}$ after activation under $\mathrm{N}_{2}$.

Spectroscopic measurements. IR spectra were recorded using a Nicolet iS10 FTIR spectrometer. In situ IR spectra were taken with an air-tight homemade IR cell containing $\mathrm{KBr}$ windows. Prior to the IR measurements, high-purity $\mathrm{N}_{2}$ $(99.999 \%)$ was flowed into the sample chamber for removal of atmospheric $\mathrm{CO}_{2}$ from the IR instrument. Solid-state NMR spectroscopy was collected with a Bruker AVANCE II $+400 \mathrm{MHz}$ NMR system at KBSI Seoul Western Center.

Isosteric heats of adsorption calculations. We employed the dual-site L-F equation (Eq. (2)) to analyze the $\mathrm{CO}_{2}$ adsorption characteristics in the whole range of the isotherm for een-MOF/Al and een-MOF/Al-Si:

$$
q=\frac{q_{\mathrm{sat}, \mathrm{A}} b_{\mathrm{A}} p^{\alpha \mathrm{A}}}{1+b_{\mathrm{A}} p^{\alpha \mathrm{A}}}+\frac{q_{\mathrm{sat}, \mathrm{B}} b_{\mathrm{B}} p^{\alpha \mathrm{B}}}{1+b_{\mathrm{B}} p^{\alpha \mathrm{B}}}
$$

here, $q$ represents the amount of $\mathrm{CO}_{2}\left(\mathrm{mmol} \mathrm{g}^{-1}\right), p$ the pressure (bar), $q_{\text {sat }}$ the saturation amount $\left(\mathrm{mmol} \mathrm{g}^{-1}\right), b$ the L-F parameter $\left(\mathrm{bar}^{-\alpha}\right)$, and $\alpha$ the L-F exponent (dimensionless) toward two adsorption sites $\mathrm{A}$ and $\mathrm{B}$ :

$$
(\ln p)_{q}=\left(\frac{Q_{\mathrm{st}}}{R}\right)\left(\frac{1}{T}\right)+C
$$

The isotherm fits were utilized to determine the exact pressures, $p$, corresponding to constant amounts of $\mathrm{CO}_{2}$ adsorbed, $q$, at three temperatures. The Clausius-Clapeyron equation (Eq. (3)) was applied to attain the isosteric heats of adsorption $\left(Q_{\mathrm{st}}\right)$.

\section{Data availability}

The data supporting the observations of this work are included in this paper and its Supplementary information.

Received: 24 August 2020; Accepted: 25 November 2020;

Published online: 04 January 2021

\section{References}

1. Karl, T. R. \& Trenberth, K. E. Modern global climate change. Science 302, 1719-1723 (2003).
2. Sumida, K. et al. Carbon dioxide capture in metal-organic frameworks. Chem Rev. 112, 724-781 (2012).

3. Pera-Titus, $\mathrm{M}$. Porous inorganic membranes for $\mathrm{CO}_{2}$ capture: present and prospects. Chem. Rev. 114, 1413-1492 (2014).

4. Bui, M. et al. Carbon capture and storage (CCS): the way forward. Energy Environ. Sci. 11, 1062-1176 (2018).

5. Rochelle, G. T. Amine scrubbing for $\mathrm{CO}_{2}$ capture. Science 325, 1652-1654 (2009).

6. Figueroa, J. D., Fout, T., Plasynski, S., McIlvried, H. \& Srivastava, R. D. Advances in $\mathrm{CO}_{2}$ capture technology-the U.S. Department of Energy's Carbon Sequestration Program. Int. J. Greenh. Gas Control 2, 9-20 (2008).

7. Choi, S., Drese, J. H. \& Jones, C. W. Adsorbent materials for carbon dioxide capture from large anthropogenic point sources. ChemSusChem 2, 796-854 (2009).

8. D’Alessandro, D. M., Smit, B. \& Long, J. R. Carbon dioxide capture: prospects for new materials. Angew. Chem. 49, 6058-6082 (2010).

9. Bollini, P., Didas, S. A. \& Jones, C. W. Amine-oxide hybrid materials for acid gas separations. J. Mater. Chem. 21, 15100-15120 (2011).

10. Pardakhti, M. et al. Trends in solid adsorbent materials development for $\mathrm{CO}_{2}$ Capture. ACS Appl. Mater. Interfaces 11, 34533-34559 (2019).

11. Ding, M., Flaig, R. W., Jiang, H. L. \& Yaghi, O. M. Carbon capture and conversion using metal-organic frameworks and MOF-based materials. Chem. Soc. Rev. 48, 2783-2828 (2019).

12. Choi, W. et al. Epoxide-functionalization of polyethyleneimine for synthesis of stable carbon dioxide adsorbent in temperature swing adsorption. Nat. Commun. 7, 12640 (2016).

13. Min, K., Choi, W., Kim, C. \& Choi, M. Oxidation-stable amine-containing adsorbents for carbon dioxide capture. Nat. Commun. 9, 726 (2018).

14. Liang, W. et al. A tailor-made interpenetrated MOF with exceptional carboncapture performance from flue gas. Chem 5, 950-963 (2019).

15. Li, J., Bhatt, P. M., Li, J., Eddaoudi, M. \& Liu, Y. Recent progress on microfine design of metal-organic frameworks: structure regulation and gas sorption and separation. Adv. Mater. 32, 2002563 (2020).

16. McDonald, T. M. et al. Capture of carbon dioxide from air and flue gas in the alkylamine-appended metal-organic framework mmen- $\mathrm{Mg}_{2}(\mathrm{dobpdc})$. J. Am. Chem. Soc. 134, 7056-7065 (2012).

17. McDonald, T. M. et al. Cooperative insertion of $\mathrm{CO}_{2}$ in diamine-appended metal-organic frameworks. Nature 519, 303-308 (2015).

18. Lee, W. R. et al. Exceptional $\mathrm{CO}_{2}$ working capacity in a heterodiamine-grafted metal-organic framework. Chem. Sci. 6, 3697-3705 (2015).

19. Lee, W. R. et al. Diamine-functionalized metal-organic framework: exceptionally high $\mathrm{CO}_{2}$ capacities from ambient air and flue gas, ultrafast $\mathrm{CO}_{2}$ uptake rate, and adsorption mechanism. Energy Environ. Sci. 7, 744-751 (2014).

20. Mao, V. Y. et al. Cooperative carbon dioxide adsorption in alcoholamine- and alkoxyalkylamine-functionalized metal-organic frameworks. Angew. Chem. https://doi.org/10.1002/anie.201915561 (2020).

21. Zhang, H., Yang, L. M. \& Ganz, E. Adsorption properties and microscopic mechanism of $\mathrm{CO}_{2}$ capture in 1,1-dimethyl-1,2-ethylenediamine-grafted metal-organic frameworks. ACS Appl. Mater. Interfaces 12, 18533-18540 (2020).

22. Joss, L., Hefti, M., Bjelobrk, Z. \& Mazzotti, M. On the potential of phasechange adsorbents for $\mathrm{CO}_{2}$ capture by temperature swing adsorption. Energy Procedia 114, 2271-2278 (2017)

23. Pai, K. N., Baboolal, J. D., Sharp, D. A. \& Rajendran, A. Evaluation of diamine-appended metal-organic frameworks for post-combustion $\mathrm{CO}_{2}$ capture by vacuum swing adsorption. Sep. Purif. Technol. 211, 540-550 (2019).

24. Jo, H. et al. Fine-tuning of the carbon dioxide capture capability of diaminegrafted metal-organic framework adsorbents through amine functionalization. ChemSusChem 10, 541-550 (2017).

25. Milner, P. J. et al. Overcoming double-step $\mathrm{CO}_{2}$ adsorption and minimizing water co-adsorption in bulky diamine-appended variants of $\mathrm{Mg}_{2}$ (dobpdc). Chem. Sci. 9, 160-174 (2018)

26. Inagaki, F., Matsumoto, C., Iwata, T. \& Mukai, C. $\mathrm{CO}_{2}$-selective absorbents in air: reverse lipid bilayer structure forming neutral carbamic acid in water without hydration. J. Am. Chem. Soc. 139, 4639-4642 (2017).

27. Milner, P. J. et al. A diaminopropane-appended metal-organic framework enabling efficient $\mathrm{CO}_{2}$ capture from coal flue gas via a mixed adsorption mechanism. J. Am. Chem. Soc. 139, 13541-13553 (2017).

28. Lee, W. R. et al. Diamine-functionalization of a metal-organic framework adsorbent for superb carbon dioxide adsorption and desorption properties. ChemSusChem 11, 1694-1707 (2018).

29. Siegelman, R. L. et al. Water enables efficient $\mathrm{CO}_{2}$ capture from natural gas flue emissions in an oxidation-resistant diamine-appended metal-organic framework. J. Am. Chem. Soc. 141, 13171-13186 (2019).

30. Choe, J. H. et al. Revealing an unusual temperature-dependent $\mathrm{CO}_{2}$ adsorption trend and selective $\mathrm{CO}_{2}$ uptake over water vapors in a 
polyamine-appended metal-organic framework. Mater. Chem. Front. 3, 2759-2767 (2019).

31. Kang, M. et al. A diamine-grafted metal-organic framework with outstanding $\mathrm{CO}_{2}$ capture properties and a facile coating approach for imparting exceptional moisture stability. J. Mater. Chem. A 7, 8177-8183 (2019).

32. Liu, X., Xie, L. \& Wu, Y. Recent advances in the shaping of metal-organic frameworks. Inorg. Chem. Front. 7, 2840-2866 (2020).

33. Mallick, A. et al. Advances in shaping of metal-organic frameworks for $\mathrm{CO}_{2}$ capture: understanding the effect of rubbery and glassy polymeric binders. Ind. Eng. Chem. Res. 57, 16897-16902 (2018).

34. Carne-Sanchez, A., Imaz, I., Cano-Sarabia, M. \& Maspoch, D. A. spray-drying strategy for synthesis of nanoscale metal-organic frameworks and their assembly into hollow superstructures. Nat. Chem. 5, 203-211 (2013).

35. Kang, M., Kang, D. W. \& Hong, C. S. Post-synthetic diaminefunctionalization of MOF-74 type frameworks for effective carbon dioxide separation. Dalton Trans. 48, 2263-2270 (2019).

36. Siegelman, R. L. et al. Controlling cooperative $\mathrm{CO}_{2}$ adsorption in diamineappended $\mathrm{Mg}_{2}$ (dobpdc) metal-organic frameworks. J. Am. Chem. Soc. 139, 10526-10538 (2017).

37. Luz, I., Soukri, M. \& Lail, M. Synthesis of fluidized $\mathrm{CO}_{2}$ sorbents based on diamine coordinated to metal-organic frameworks by direct conversion of metal oxides supported on mesoporous silica. Chem. Eur. J. 24, 10612-10616 (2018).

38. Darunte, L. A. et al. Monolith-supported amine-functionalized $\mathrm{Mg}_{2}(\mathrm{dobpdc})$ adsorbents for $\mathrm{CO}_{2}$ capture. ACS Appl. Mater. Interfaces 9, 17042-17050 (2017).

39. Bou, M., Martin, J. M. \& Le Mogne, T. Chemistry of the interface between aluminiumand polyethyleneterephthalate by XPS. Appl. Surf. Sci. 47, 149-161 (1991).

40. Sun, Z. et al. A facile fabrication of mesoporous core-shell CaO-based pellets with enhanced reactive stability and resistance to attrition in cyclic $\mathrm{CO}_{2}$ capture. J. Mater. Chem. A 2, 16577-16588 (2014).

41. Knight, A., Ellis, N., Grace, J. R. \& Lim, C. J. $\mathrm{CO}_{2}$ sorbent attrition testing for fluidized bed systems. Powder Technol. 266, 412-423 (2014).

42. Wang, J. et al. Hydration energetics of a diamine-appended metal-organic framework carbon capture sorbent. J. Phys. Chem. C 124, 398-403 (2019).

43. Kujawa, J. et al. Efficiency of grafting of $\mathrm{Al}_{2} \mathrm{O}_{3}, \mathrm{TiO}_{2}$ and $\mathrm{ZrO}_{2}$ powders by perfluoroalkylsilanes. Colloids Surf. A Physicochem. Eng. Asp. 420, 64-73 (2013).

44. Martell, J. D., Milner, P. J., Siegelman, R. L. \& Long, J. R. Kinetics of cooperative $\mathrm{CO}_{2}$ adsorption in diamine-appended variants of the metal-organic framework $\mathrm{Mg}_{2}$ (dobpdc). Chem. Sci. 11, 6457-6471 (2020).

45. Forse, A. C. et al. Elucidating $\mathrm{CO}_{2}$ chemisorption in diamine-appended metalorganic frameworks. J. Am. Chem. Soc. 140, 18016-18031 (2018)

46. Bemrose, C. R. \& Bridgwater, J. A. Review of attrition and attrition test methods. Powder Technol. 49, 97-126 (1987).

\section{Acknowledgements}

This work was supported by a Korea CCS R\&D Center (KCRC) grant funded by the Korean Government (the Ministry of Science, ICT, \& Future Planning (MSIP)) (NRF2012-0008901), the Basic Science Research Program (NRF-2018R1A2A1A05079297), and the Priority Research Centers Program (NRF-2019R1A6A1A11044070).

\section{Author contributions}

C.S.H. conceived the project. J.H.C. conducted experiments including sample synthesis and characterizations by PXRD, gas isotherms, SEM, and XPS data with assistance of H.K. and M.K.; J.R.P., Y.S.C., and D.S.C. fabricated MOF beads under the guidance of H.S. and Y.-K.P.; D.W.K. prepared and characterized the ligand. J.H.C. and C.S.H. wrote the paper. All authors contributed to discussions and finishing the paper.

\section{Competing interests}

The authors declare no competing interests.

\section{Additional information}

Supplementary information is available for this paper at https://doi.org/10.1038/s43246020-00109-8.

Correspondence and requests for materials should be addressed to C.S.H.

Peer review information Primary handling editor: John Plummer.

Reprints and permission information is available at http://www.nature.com/reprints

Publisher's note Springer Nature remains neutral with regard to jurisdictional claims in published maps and institutional affiliations.

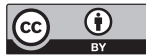

Open Access This article is licensed under a Creative Commons Attribution 4.0 International License, which permits use, sharing, adaptation, distribution and reproduction in any medium or format, as long as you give appropriate credit to the original author(s) and the source, provide a link to the Creative Commons license, and indicate if changes were made. The images or other third party material in this article are included in the article's Creative Commons license, unless indicated otherwise in a credit line to the material. If material is not included in the article's Creative Commons license and your intended use is not permitted by statutory regulation or exceeds the permitted use, you will need to obtain permission directly from the copyright holder. To view a copy of this license, visit http://creativecommons.org/ licenses/by/4.0/.

(C) The Author(s) 2021 